\title{
Is South Africa Ready to Be a Developmental State?
}

DE WEE, Khotso

\section{Introduction}

Developmental state is often conceptually positioned between liberal open economy model and a central-planned model. The theory of developmental state isn't capitalist or socialist. The developmental state is based on combinations of positive advantages private business and the positive role of government (Bolesta, 2007: 105).

Developmental states are concepts used by International Political Economist in referring to macro-economic policies that champions growth, development and industrialisation by the government. Hence, characterised by a viable intervention, extensive regulation and planning by the state. The concept is a contraption of the development in East Asia, Japan and Botswana since the 1970s (Leftwich, 1994). The term was first conceptualised by Chalmers Johnson in 1980s (Öniş, 1991), where he defined a developmental state "as a state that is focused on economic development and takes necessary policy measures to accomplish that objective.

The idea of a regulatory state differs from a developmental state, in that, while the argument of a regulatory state is governed by empowered regulatory agencies that ensure that the variety of abysmal standards of behaviour are protected in the interest of the public. Premised on four major market forces, monopoly, pricing, predation, and other abuses of market power, and the provision of commodities for collective goods. That of a developmental state is a direct intervention in the economy through the promotion of new industries and the reduction of dislocations caused by the shifts in profits and investment. Arguably, while a developmental state pursues the promotion of industrial policies, regulatory states generally cannot (Evans, 1995). 
The current South African government has proposed to transform itself into a developmental state (See Edigheji, 2010; and the NDP, 2012). This proposal is viewed as a panacea that will enable the government to build critical capabilities that will enable it to eradicate the legacy of apartheid and its consequent manifestations of poverty and inequality.

This proposal is largely inspired by the experiences of South East Asian countries such as Hong Kong, Malaysia, Singapore, Taiwan and South Korea that, to a great degree, eradicated poverty and ushered an era of unprecedented economic development in those countries.

Recent literature demonstrates that there are numerous factors that shape a developmental state. Key amongst which is the ideology, the bureaucratic competency, the interaction between the bureaucracy and the political class, the management of the interaction between the government and civil society, the relationship between democracy and development, and the credibility and the legitimacy of the state to manage the relationship between itself, as well as amongst non-state actors in pursuit of its developmental goals.

In exploring the feasibility of the developmental state thesis in South Africa, this essay will consider the key qualities of developmental states, their presence or absence in the architecture of the South African democracy, and key areas that need attention for South Africa to be a truly developmental state.

\section{Key Features of a Developmental State}

\section{Strategic Orientation}

The developmental state, according to Mkandawire (2001: 290), has ideological and structural components that distinguish it from other forms of states. With regard to the ideological component, the state assumes a developmentalist character in which it conceives its mission as that of ensuring economic development and the associated high rates of accumulation and industrialization. The state/structure component, on the other hand, implies the state has the requisite capacity to implement economic policies efficiently and effectively.

According to Netshitenzhe (2015), a developmental state could be a way out of the pedestrian economic growth and development in which South Africa currently finds itself. 
Such a state, however, should have a 'strategic orientation for development, premised on the political will for the leadership to stake there all on a developmental project' (Netshitenzhe, 2015: 555). Edigheji (2010: 1) similarly observes that the African National Congress, which is South Africa's governing party, resolved in its National General Council of 2005, policy conference of 2007 and the national election manifesto of 2009 that it is going to build a developmental state that will play a central and strategic role by directly investing in underdeveloped areas and directing private sector investment, and will play a critical role in addressing the problems of high unemployment, poverty and inequality.

Evans (2011: 9) suggests that there is a need to build a theory of a developmental state that responds to the challenges created by reconceptualising development as capability expansion. Pinning his colours to the Senian mast (See Sen, 1999), he reconceptualises the role of the developmental state as expanding capabilities like education, health, infrastructure and social services rather than narrowly focusing on economic growth and industrialization.

Such re-conceptualisation has profound implications for the role of the developmental states. According to Evans and Heller (2013: p.7), industrial growth can be achieved by aligning with a fairly narrow group, deploying familiar policy instruments such as subsidies, interest rates and state procurement; and can be measured against hard indicators such as exports and manufacturing output. They argue, however, that:

Delivery of high quality services requires interventions that are deeper and more socially and politically intrusive than industrial policy. Because capability-enhancement is about removing un-freedoms, it butts up directly against forms of traditional authority and organized power of clans, castes, patriarchs, and challenges the political hegemony of capitalist elites as well. A state that can deliver such services is one that must have both significant infrastructural powerthe power to reach into society and deliver things-as well as significant authoritative power-the power to get individuals and groups to willingly obey commands (Evans and Heller, 2013: 8). 


\section{Co-ordination}

The developmental state must have legitimacy to mobilize society behind a vision and programs to attain such developmental objectives, and provide what Netshitenzhe (2015) call ideational leadership or hegemony. Naseemullah and Arnold (2014) similarly observes that:

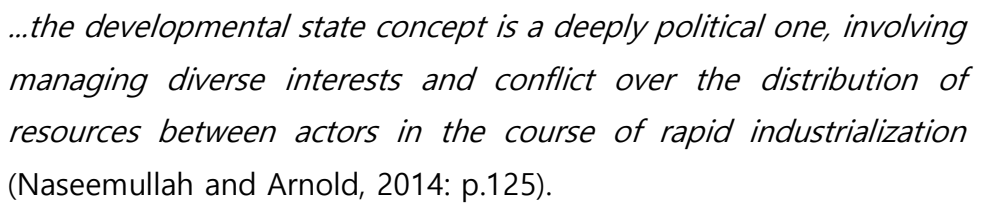

The management of these diverse interests is critical as they can empower or undermine the state's ability to achieve its developmental goals. At the moment the South African government is perceived to be falling short of playing its leadership and coordination role in this regard. Fine (2010), for example, observes that... 'far from the developmental state coordinating or even coercing private capital to commit to a concerted program of industrial expansion and diversification, the interests of private capital have predominated over developmental goals. For the first decade of the postapartheid economy, macro-economic orthodoxy has prevailed at the expense of broader economic and social interventions' (Fine, 2010: p.175). It is important to recall that this was ever before allegations of state capture were made by the South African media (Mail and Guardian, 2016)

Naseemullah and Arnold (2014: p. 129) cautions that:

...effective challenges to developmental state institutions-even
decades after their establishment-can result in an abrupt end to self-
sustaining industrial development. The continuing consensus behind
industrialization led Korea and Taiwan to maintain commitments to
industrial investment and upgrade successfully, whereas
fragmentation of support in Pakistan and Turkey prevented such
upgrading. We argue that such fragmentation in the latter cases came
primarily as a result of the resurgence of politically salient provincial
actors who sought redistribution of resources away from narrow,
privileged bourgeoisies in Istanbul and Karachi. Such counter-
mobilisation effectively challenged the consensus around the state-


led industrialization, whereas the absence of equivalent conflict in East

Asia maintained these countries industrial trajectories.

Netshitenzhe (2015) is alive to these risks and advocates that the state as a whole should have the will to break logjams in the interactions among various sectors of society in order to prevent narrow sectoral interests from paralyzing broader societal interests. Whilst he appreciates that structures such as South Africa's National Economic and Development Labour Council (NEDLAC) were set up primarily to resolve critical issues amongst social partners, he observes that it is not achieving its mandate because each constituency pursues frozen mandates, representation has been juniorised, and the interactions are technocratic.

\section{Technical Capacity}

The technical capacity of the state to achieve its developmental objectives is one of the critical features of a developmental state. Netshitenzhe (2015) emphasizes that one of the critical and necessary attributes of a developmental state is a central institution with strategic capacities, leverages and authority to drive economic development policy and ensure its implementation. He observes, however, that one of the weaknesses of the current South African state is the multiplicity of centres from which economic policy is driven. These include the departments of Economic Development, Trade and Industry, National Treasury, Public Enterprises, etc. Similarly, Naasemullah and Arnold (2014: p.124) acknowledge that developmental state institutions include bureaucratic and meritocratic state agencies, the presence of thick external ties to private businesses, and the willingness and the capacity of the state to discipline business and labour while appreciating their indispensability to industrialization.

According to Edigheji (2010: 4), it is institutions that will determine a democratic developmental state's capacity to formulate and implement its policy and programs. He adds that such a state has to be able to construct and deploy the institutional architecture within the state and mobilize society towards the realization of a developmentalist project. Bureaucratic competence is an important quality of developmental states, and a critical source of such competence is recruiting staff based on merit and long-term career rewards (Edigheji, 2010: p.7).

Bureaucratic agencies created to implement developmental policies and programs needs to be insulated from sectional interests to avoid dominance and ultimate capture 
by these interests. Such insulation will enable the state to take a long-term view of national development as well as enabling public agencies to act as coherent and collective entities (Edigheji, 2010: p.7).

\section{The Relationship between Democracy and Development}

Whilst competent bureaucracies are critical in enabling a developmental state to pursue its goals, they are not a sufficient condition for a developmental state. Edigheji (2010: p.8) draws our attention to the importance of the political capacity to enable the state to act legitimately and in a manner that engenders both transparency and accountability. $\mathrm{He}$ adds that such capacity also enhances the capacity of a developmental state to mobilize society and to build consensus around its developmental project.

Whilst creating an institutional apparatus to deliver on a country's developmental goals is important, we are reminded that a developmental state in South Africa must be conceptualized in a multi-dimensional and holistic manner to engender economic freedom, social freedom, political freedom and environmental sustainability. This conceptualization, may enable an aspirant developmental state like South Africa to pursue industrialization without neglecting social transformation which may encompass reduction of poverty, inequality and high levels of unemployment (Edigheji, 2010: p.10).

A re-conceptualised role of the developmental state by theorists such as Evans (2011) proposes that the ability of the state to pursue collective goals coherently, in tandem with all key actors of society rather than responding to subjectively defined immediate demands of individual members of the elite, or particular elite organizations, is more essential than ever before.

In trying to explain South Africa's inability to gain traction as a 21st century developmental state in terms of expanding human capabilities compared to other middle income countries such as Brazil, the inadequacy of the relationship and interaction between 'political society' (meaning the state as a political entity and political parties) and civil society provides part of the explanation. It is observed that participatory structures that were part of the architecture of South Africa's new democracy were dismantled or hollowed out after the ANC unilaterally embraced Neo-liberal reforms in 1996 and turned to a much more technocratic and managerialist strategy of service delivery. The increase in service delivery protests is partly attributed to this marginalization of civil society (Evans and Heller 2013). This evoked the conclusion that: 
Technocratic and organizational capacities are still fundamental to the success of the developmental state, but absent a complementary politics of encompassing engagement with a broad section of society, technocratic capacity is sterile and ineffectual. In building a politics of capability expansion, the state itself cannot be the only actor, nor can it rely on elite allies. Absent an effective conglomerate of societal actors capable of embodying the role intrinsic to 'civil society' as an ideal type, the developmental state cannot deliver capability expansion (Evans and Heller, 2013: p.28).

Mathebula (2016: p.54) similarly advocates for a model that would be bottom-up and include all key societal stakeholders in negotiating an economic development path.

\section{Is South Africa Ready to be a Developmental State?}

Mkandawire (2001) has urged that it is not impossible for Africa to have developmental states. This is despite the observation that:

... what has obviously worked in other 'late industrialisers' is simply a non-starter in Africa. While it is now admitted that the state has played a central role in the development of Asian countries, it is suggested that replication of the Asian experience is somehow impossible for Africa. The reasons include (a) dependence, (b) the lack of ideology (c) the softness of the African state and its proneness to capture by special interest groups, (d) lack of technical and analytical capacity, (e) the changed international environment that did not permit protection of industrial policies, and (f) the poor record of past performance (Mkandawire, 2001: p.294).

Efforts on the part of the South African government, and the presence of resources and key attributes of the current South African state make the dream achievable. Hence, there are a number of attributes and advantages present in the new democracy's architecture that makes it plausible for South Africa to be a developmental state. 
Emerging Issues in Public Sector Reforms in Africa: An Assessment of Ghana and Nigeria 495

\section{The National Development Plan}

The South African government has developed a National Development Plan, which defines its vision 2030. It provides a strategic orientation that Mkandawire (2001), Edigheji (2010) and Netshitenzhe (2015) cited as important above. The South African government proclaims that:

The National Development Plan aims to eliminate poverty and reduce inequality by 2030. South Africa can realize these goals by drawing on the energies of its people, growing an inclusive economy, building capabilities, enhancing the capacity of the state, and promoting leadership and partnerships throughout society (NDP2030 2012: 14).

Like Evans (2011) advises, the NDP draws extensively on the notion of capabilities. It cites the following capabilities as critical for development:

- Political freedoms and human rights;

- Social opportunities arising from education, health care, public transport, and other public services;

- Social security and safety nets;

- An open society, transparency, disclosures and a culture of accountability; and

- Economic facilities, work, consumption, exchange, investment and production (NDP, 2012: 17)

The South Africa envisaged in 2030 in the National Development Plan is a developmental state that strives to build the capabilities of people to improve their own lives, while intervening to correct historical inequalities. (NDP, 2012: 17).

Whilst work has begun in various government departments to integrate the vision of the NDP into its strategic plans, visible leadership is required to match the dream of Vision 2030 with the daily reality of poverty, social inequality and high levels of unemployment amongst ordinary South African citizens.

Apart from leadership and management that is required to make the dream of NDP come true, a lot more is needed in terms of making optimal use of South Africa's bureaucratic capacity, its strong and diverse private sector and civil society to build capabilities that will make South Africa a truly capable state. 


\section{South Africa's strengths}

South Africa is a democratic state, and the current government draws its legitimacy from being elected into government by the majority of South Africans. The three arms of the state, i.e., the Executive, the Legislature, and the Judiciary are functioning reasonably well. Despite some service delivery protests and challenges, the same could be said about the three tiers of government, i.e., the national, provincial and local government.

South Africa also has a well-developed and diverse private sector, which, if sufficiently mobilized, can play a major role in the implementation of the National Development Plan and potentially achieve the growth targets agreed upon in the plan.

South Africa's Minister of Finance, in his 2016 Budget Speech, added that the country has the following advantages, amongst others:

- The macro-economic policy is effective;

- The inflation targeting framework provides an anchor for price and wage setting;

- Our banks and financial institutions are well capitalized, and we have liquid randdenominated debt markets;

- The architecture of our Constitution, justice system, public and private law and dispute resolution mechanisms is robust;

- We have excellent universities and research centres; and

- We have a strong private sector (Gordhan, 2016).

The 2016 Budget speech further added that, as part of implementing the National Development Plan and creating capabilities, there is focus on both basic education and post-school education and training, infrastructure development, social protection and health services (Gordhan, 2016).

\section{Key Weaknesses}

The above advantages need to be viewed against key weaknesses that the country is currently experiencing. The march towards eradicating poverty and reducing unemployment is halted by poor economic growth. According to South Africa's Minister of Finance's 2016 budget speech, the South African economy is expected to grow by a mere $0.9 \%$ compared to $1.3 \%$ in 2015 (Gordhan, 2016). Stats South Africa estimates the unemployment rate to be $26.7 \%$ (Stats South Africa, 2016). The International Monetary Fund has raised concerns about the growth forecast of $0.1 \%$ against the annual population increase of $1.7 \%$. The institution further indicated that the exclusion of one third of South 
Africa's working population is not in the country's best interest (Lipton, 2016). These socioeconomic indicators suggest that, unlike the Asian tigers mentioned above, South Africa has not reached a point where it can be classified as a developmental state.

There are other potential hurdles that needs to be attended to by the South African government. Netshitenze (2015), Mkhandawire (2001), and Naseemullah and Arnold (2014) emphasized the importance of a functioning bureaucracy in meeting the developmental goals of the state. Karl van Holdt (2010), however, draws attention to the significant challenges faced by the South African public service. He indicates that certain departments, though not all, are crisis ridden and unable to deliver services due to loss of skills, lack of expertise and institutional memory, numerous vacancies in senior positions and endemic corruption. While South Africa's Auditor-General has noted improvements in the form of $28 \%$ of government departments attaining unqualified audit opinions in 2015, as opposed to $26 \%$ in 2014, like Van Holdt (2010), the Auditor-General raised concerns about:

- The slow response by management to implement plans to address deficiencies in financial controls based on commitments already made;

- Providing effective leadership and monitoring achievement of performance targets;

- Reviewing and monitoring compliance with key laws and legislation over financial matters;

- Wasteful and Fruitless expenditure;

- Supply chain management weakness; and

- The number of departments with qualified and disclaimed financial statements (AGSA, 2015).

Until the South African public service has overcome these challenges, the government's ambition to be a developmental state is far from being realized.

We also need to take heed of Netshitenzhe (2015: p.559)'s warning that:

Unethical conduct by leaders in government, business, the trade union movement and the rest of civil society, impressions of lack of respect for public resources, and the ostentation of the elite 
delegitimize not only the party political and societal leadership, but also the state...

Gumede (2015: 592) adds that the ANC's organizational culture has a dominant influence on the culture of public administration. Whilst there are positive developments like emphasis on the need to consult communities on matters that affects them, he draws our attention to the negative aspects of this culture. He cites examples such as micro management of governance, ANC leaders assuming to be above democratic institutions and bureaucracy, politician's access to and control of public resources, and centralization of policies, decisions and appointments. He concludes that:

Negative aspects of the ANC's own organizational culture have also taken root in the public service, and, combined with the apartheidera culture, have brought about a hybrid administrative culture in the public service, which has undermined efforts to make it developmental, accountable, effective and democratic, despite efforts by the democratic government to do so. The inability to transform the administrative culture of South Africa's public service is at the root of its poor performance.

\section{Can South Africa be a developmental state it aspires to be?}

Considering this question in 2016, it is clear that South Africa has advantages and disadvantages that it can work on to achieve its aspirations. First and foremost, the various arms of the state are reasonably functional. Parliament still manages to pass laws and approve budgets. The judiciary has demonstrated its independence and the decisions of the Courts are complied with. There is a system of government (national, provincial and local) that functions generally well. Government delivers a minimum amount of services required by citizens. The government is able to provide education, health and security services. The private sector is well developed, diverse and fully functional.

For South Africa to become a truly developmental state, however, there are certain conditions that South Africa need to satisfy. If not, they have a potential to derail the quest to transform South Africa into a developmental state. The following, whilst not constituting a comprehensive list, constitute some of the key weaknesses to be overcome. First and foremost, according to Netshitenzhe's (2015) and Gumede's (2015), concern that the state 
must eschew and, where justified, address the conduct of political office-bearers and government officials that threatens to delegitimize the state such as fraud and corruption, abuse of state resources and lack of respect for the country's laws, law enforcement agencies and chapter nine institutions such as the Public Protector's Office. Such incidents generate perceptions that erodes the state's moral authority and may ultimately delegitimize it.

The Government needs to strengthen its ability to manage and coordinate diverse interests central to the achievement of South Africa's developmental goals. Naseemullah and Arnold (2014), Netshitenzhe (2015) and Fine (2010) have all cautioned that the state's developmental agenda will be derailed and possibly hijacked if sectional interests dominate the agenda-setting processes. The recent allegations that private sector interests have usurped Presidential prerogatives regarding key appointments in government and parastatals have created doubts about the ability of the state to manage private sector interests (Mail and Guardian, 2016). There have been similar allegations about how certain trade unions dominate and control decision-making processes in the South African education sector (City Press, 2016). All these suggest that the state needs to take measures to restore its credibility in managing diverse interests that have a bearing on the achievement of developmental goals.

Thirdly, the bureaucratic machinery central to the achievement of developmental goals needs to be strengthened. While there are pockets of excellence acknowledged by South Africa's Auditor-General and Van Holdt (2010), there are also deficiencies that need to be remedied. These include reducing the number of vacancies, strengthening supply chain management systems, streamlining delegations of administrative power, and strengthening accountability systems.

Fourthly, the relationship between the government and civil society, as proposed by Evans (2010), needs to be revisited. The non-governmental Organizations sector has a history and reputation of being embedded in communities, and responding faster to community needs than government agencies. This relationship needs to be strengthened. Perhaps it will play a role in reducing service delivery protests, which currently are becoming very violent.

Lastly, there is a need to create vibrancy and visibility around the implementation of the National Development Plan. It is important that all sectors of the South African society including the government, the private sector, and civil society take ownership of the 
implementation of the NDP. At the moment, the government agencies have taken responsibility, but the private sector and the civil society seem left behind.

\section{Conclusion}

This essay has outlined some of the key features of State-business relations, which include among others, strategic orientation, technical capacity, and the ability to co-ordinate diverse interests. In x-raying the study in the South African context and the implication towards development for South Africa. The study has given pointers to South Africa's strengths and weaknesses. In lieu of this, the study proposes six areas through which South African can improve its gains in relation to sustaining a developmental agenda in the $21^{\text {st }}$ century. These areas are:

- Improving economic growth through state mechanism for implementation and diversification of the economy from a mono-economy;

- Strengthening and making public servants and institutions effective, efficient and accountable by ensuring that a broad range of experts are employed into the system;

- Improve the ability and the government's integrity to co-ordinate and manage diverse interests that have the possibility to promote or derail the country's developmental agenda;

- Improving relations between the government, local and international business owners and civil society;

- Strengthen the leadership character, visibility and ownership of the National Development Plan between the State, private sector and civil society; and

- Establish effective monitoring and evaluation framework like the Dashboard Theory in Monitoring (DTM) towards reducing fraud and corruption. Towards establishing State integrity, and gaining public trust.

It is on this note that the study argues that for the successful implementation of programmes and projects towards achieving a developmental state, accountability, transparency, effective governance, pluralism and political tolerance, effective monitoring 
Emerging Issues in Public Sector Reforms in Africa: An Assessment of Ghana and Nigeria 501

using the DTM as proposed by Ndaguba and ljeoma will be a suitable place to begin towards the realization of a developmental state in South Africa is germane.

\section{List of References}

- City Press newspaper. $8^{\text {th }}$ May 2016 Article titled "SADTU fights jobs-for-cash report"

- Evans, P. 1995. Embedded Autonomy: States and Industrial Transformation. Princeton: Princeton University Press.

- Evans, P (2011) 'The Capability Enhancing Developmental State: Concepts and National Trajectories'. Discussion Paper No.63. March 2011. Centre for Studies on Inequality and Development

- Evans, P and Heller, P. 2013. 'Human Development, State Transformation and the Politics of the Developmental State' in Leibfried, S. et al. 2013. The Oxford Handbook of Transformation of the State. Oxford University Press

- Edigheji, O (ed) 2010. Constructing a developmental State in South Africa: Potentials and Challenges. Cape Town. HSRC Press

- Fine, B. 2010. 'Can South Africa be a developmental state?' in Edigheji, O (ed)(2010) Constructing a developmental State in South Africa: Potentials and Challenges. Cape Town. HSRC Press

- Gumede, W. 2015. 'Administrative Culture of the South African Public Service: A Finity of Transformation' in the Journal of Public Administration. Volume 50. Number 3. September 2015

- $\quad$ Leftwich, A. 1994. "The Developmental State", Working Paper No. 6, University of York

- Leftwitch, A. "Bringing politics back in: Towards a model of the developmental state", Journal of Development Studies, Volume 31, Issue 3 February 1995, pages 400-427

- Lipton, D "Bridging South Africa's Economic Divide". A paper presented at the University of the Witwatersrand on the $19^{\text {th }}$ July 2016.

- Mail and Guardian newspaper. 18-23 March 2016 
- Mathebula N.E 'An Impossible Developmental State in the South African Context: a true reflection of Asian Tigers? In Bangladesh e-Journal of Sociology. Volume 13. Number 1. January 2016

- Mkandawire, T. 2001. 'Thinking about developmental states in Africa' in the Cambridge Journal of Economics 2001. Volume 25. p 289-313

- Naseemullah, A and Arnold, C.E. 2015. 'The Politics of Developmental State Persistence: Institutional Origins, Industrialization, and Provincial Challenge' in the Journal of Studies in Comparative International Development. Volume 50. 2015

- National Planning Commission (2012) Executive Summary: National Development Plan 2030 Presidency. Republic of South Africa

- Netshitenzhe, J. 2015. 'Class Dynamics and State Transformation in South Africa' in the Journal of Public Administration. Volume 50. Number 3. September 2015

- Ndaguba, E. A., and ljeoma, E.O.C. 2016. An argument in favour of a dashboard theory in monitoring in South Africa. ASSADPAM paper presentation.

- Öniş, Z. 1991. The Logic of the Developmental. Ph.D. Program in Political Science of the City University of New York. Comparative Politics, Vol. 24, No. 1. pp. 109-126

- Sen, A. 1999. Development as Freedom. New York. Knopf

- The Auditor-General of South Africa PFMA report. 2015 